\title{
Pd-Au Asymmetric Nanopyramids: Lateral vs Vertical Growth of Au on Pd Decahedral Seeds
}

Li Zhou, ${ }^{\dagger, *, \# ~ X i a o y u ~ Q i u, ~}{ }^{\dagger}, \#$ Zhiheng Lyu, ${ }^{\S}$ Ming Zhao, ${ }^{\S}$ and Younan Xia*,†,

†The Wallace H. Coulter Department of Biomedical Engineering, Georgia Institute of Technology and Emory University, Atlanta, Georgia 30332, United States

\$School of Physics and Technology, Wuhan University, Wuhan, Hubei 430072, P. R. China

${ }^{\S}$ School of Chemistry and Biochemistry, Georgia Institute of Technology, Atlanta, Georgia 30332, United States

${ }^{*}$ L.Z. and X.Q. contributed equally to this work.

*Address correspondence to younan.xia@bme.gatech.edu 
(a) Axial vertex
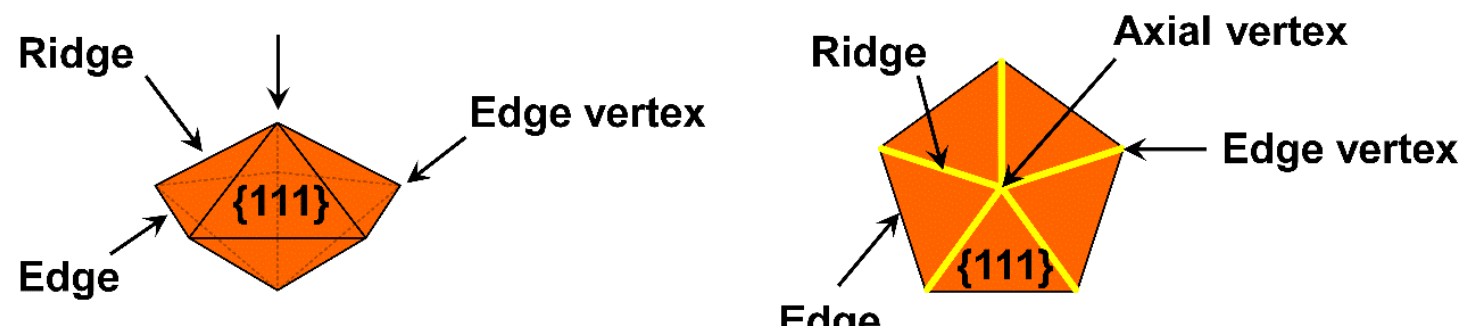

(b)

(c)
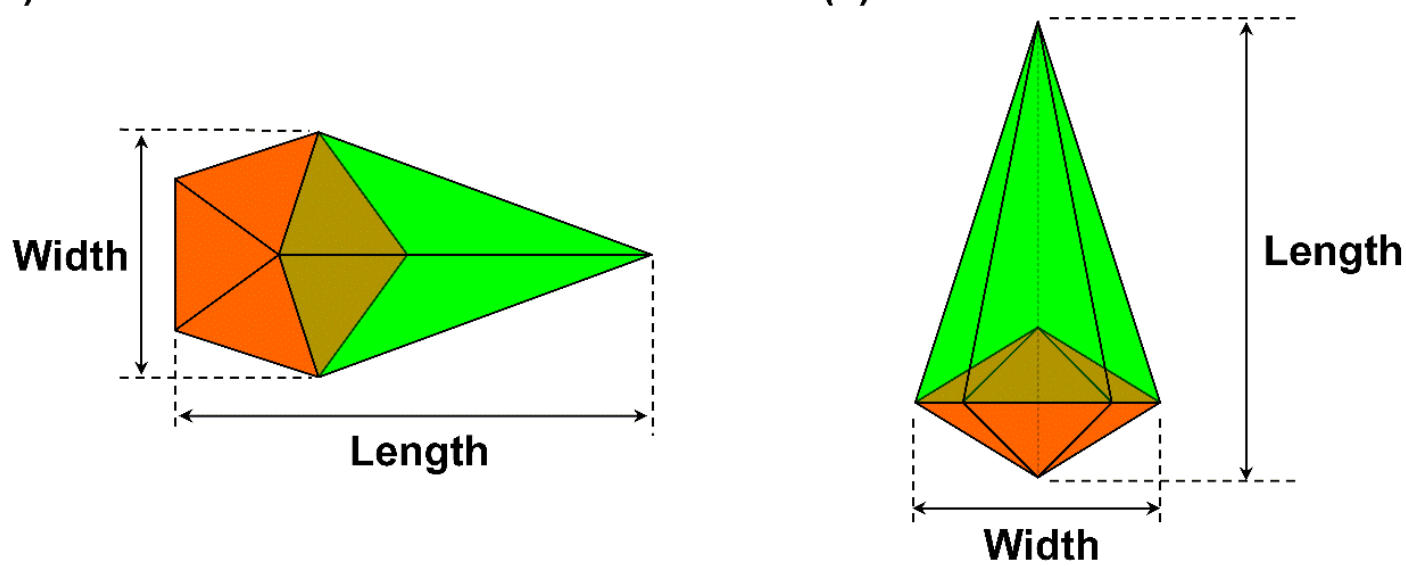

Figure S1. Schematic illustrations and definitions of the various features on (a) a decahedron, (b) a laterally-grown nanopyramid, and (c) a vertically-grown nanopyramid. The orange and green colors represent $\mathrm{Pd}$ and $\mathrm{Au}$, respectively. The yellow lines indicate the twin boundaries in the decahedron. The lateral growth is along a twin boundary, with its growth direction in the plane perpendicular to the five-fold axis. The vertical growth is along the five-fold axis. 


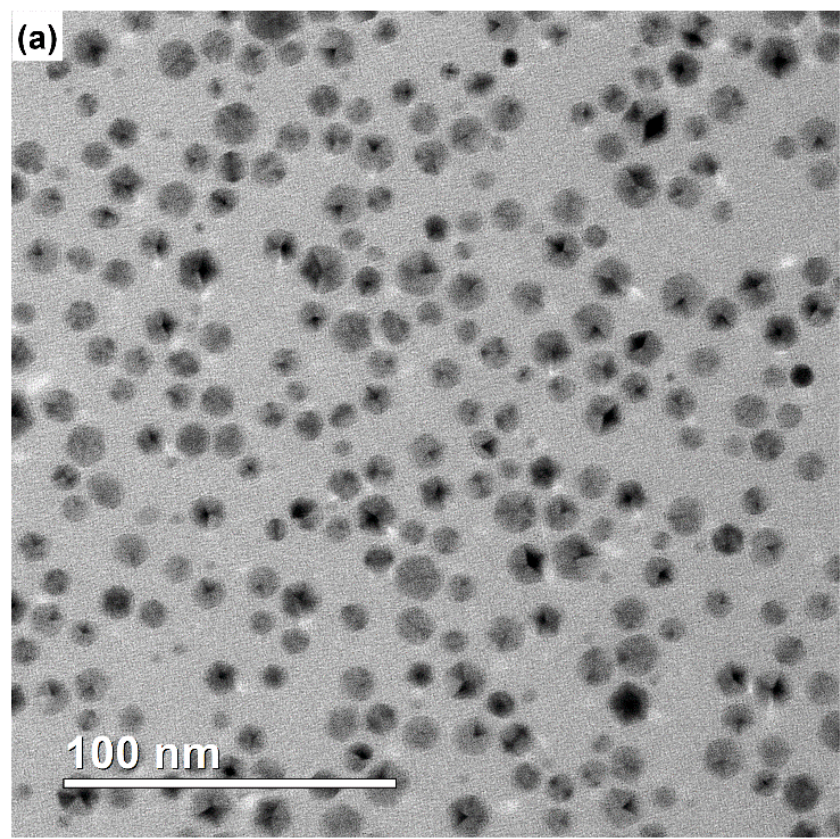

(b)

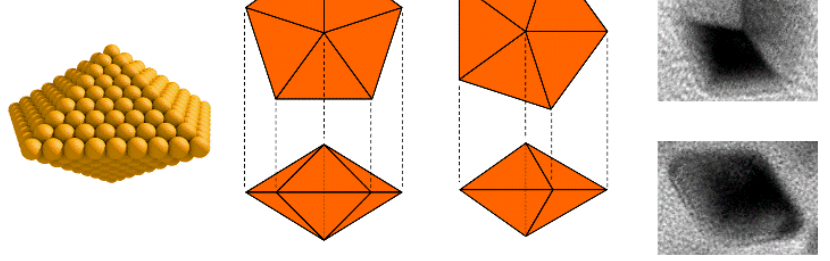

Figure S2. (a) A typical TEM image of the penta-twinned Pd decahedral seeds used for the synthesis of Pd-Au nanopyramids. (b) Schematic illustrations and TEM images of two such decahedra viewed along and perpendicular to the five-fold axis to give pentagonal and diamond shapes, respectively. 
(a)

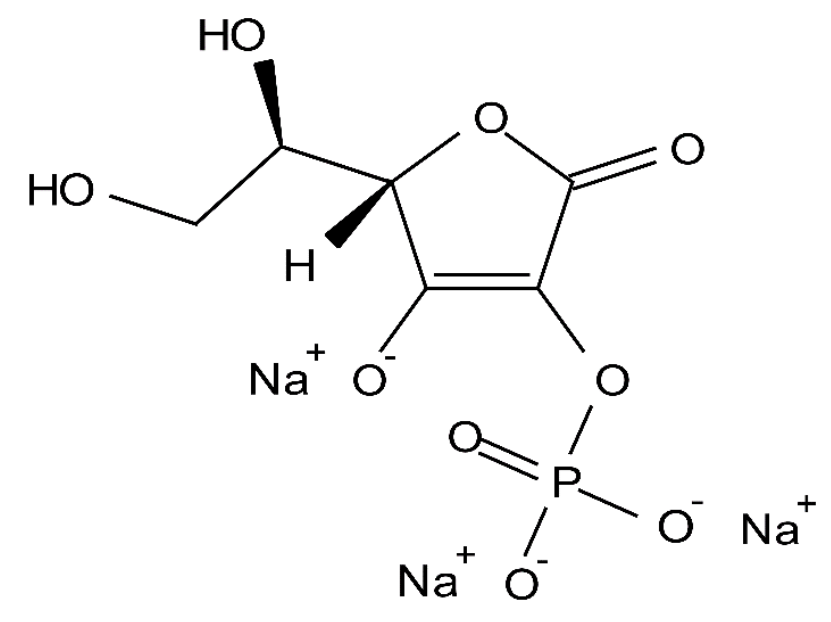

(b)

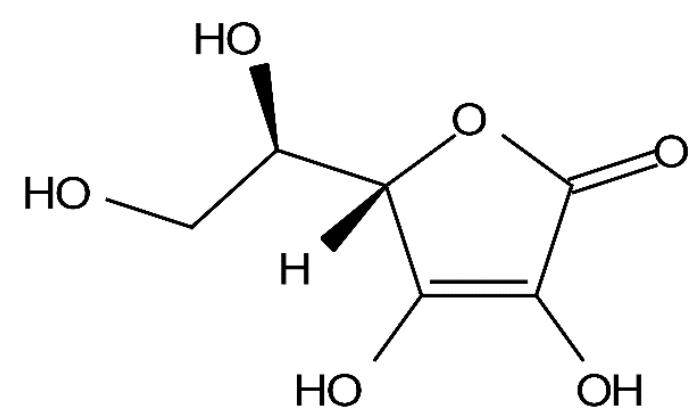

Figure S3. Molecular structures of (a) Asc-2P and (b) AA, respectively. 


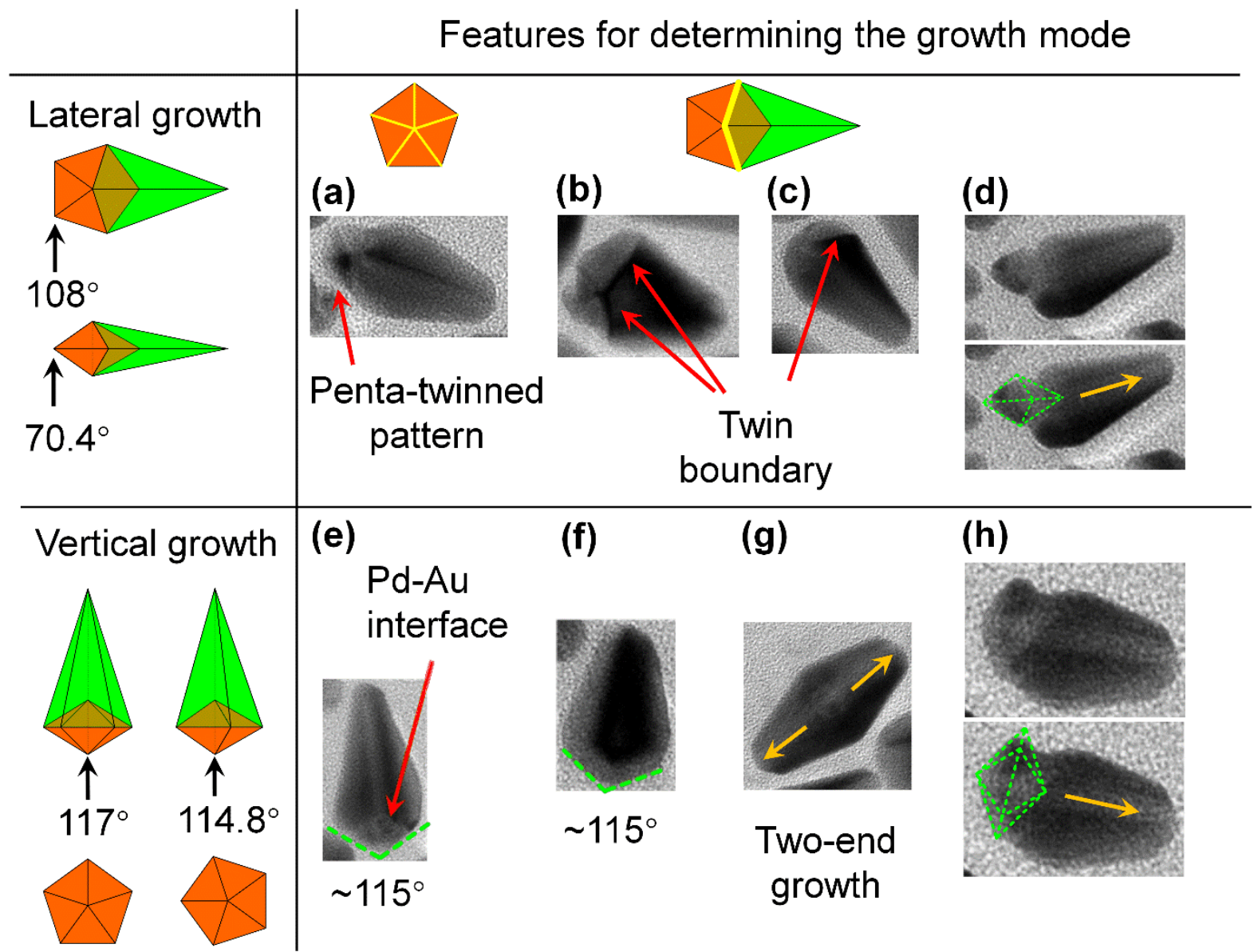

Figure S4. Some characteristic features for determining the growth mode. If the Pd decahedral seeds with a penta-twinned pattern could be identified, the growth mode would be clear (a). However, if the penta-twinned pattern of Pd seeds could not be observed, other features, such as twin boundary (b, c), end angle (e, f), Pd-Au interface (e), two-end vertical growth (g), and seed orientation $(\mathrm{d}, \mathrm{h})$ should be used to determine the growth mode. 


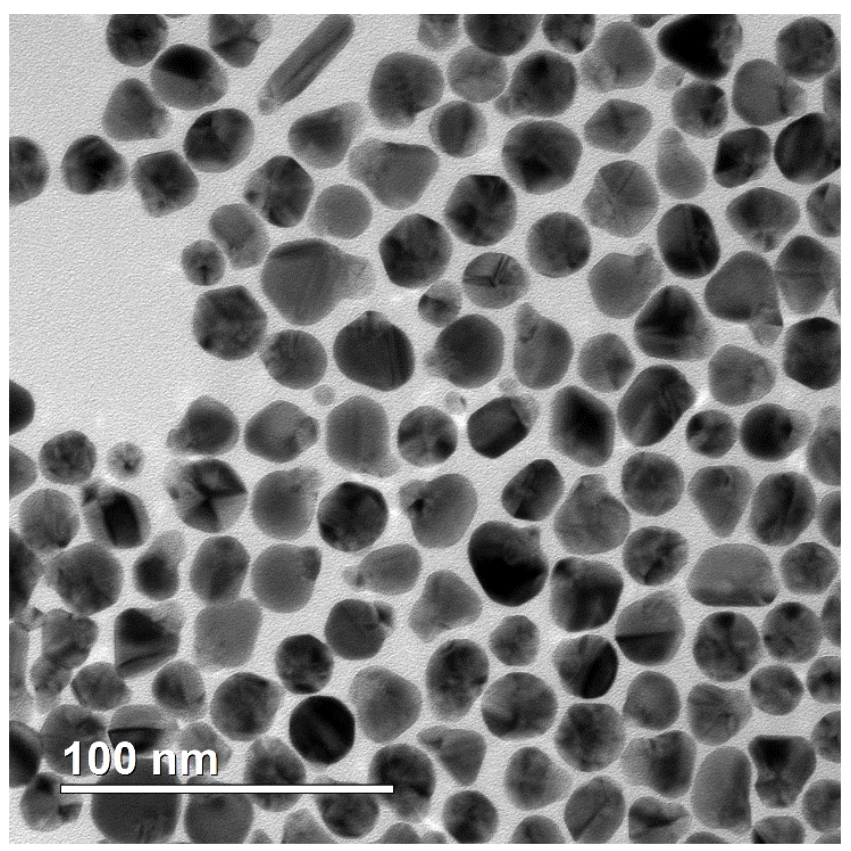

Figure S5. Pd-Au nanocrystals obtained without adding $\mathrm{AgNO}_{3}$. The particles were nearlyspherical in shape, together with a small aspect ratio, suggesting that the addition of $\mathrm{Ag}^{+}$ions was beneficial to the anisotropic growth. 

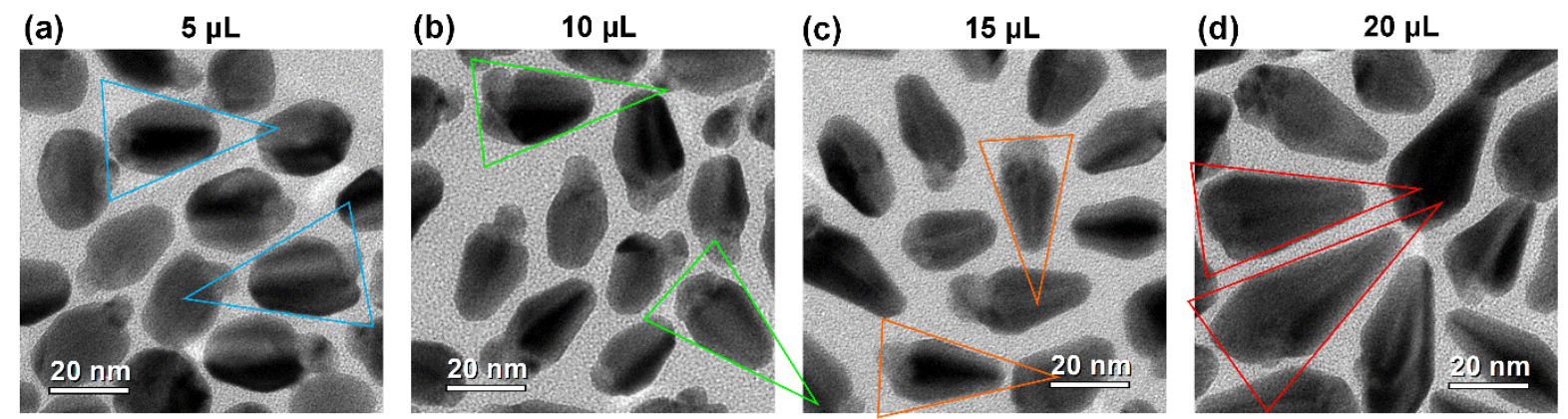

(e)

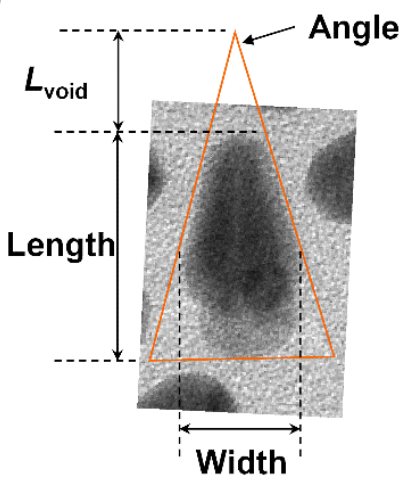

The triangle is an isosceles triangle.

$$
\begin{aligned}
& \text { Aspect Ratio }=\text { Width } / \text { Length } \\
& \text { Particle Percentage }=\text { Length } /\left(L_{\text {void }}+\text { Length }\right) \\
& \text { Void Percentage }=L_{\text {void }} /\left(L_{\text {void }}+\text { Length }\right)
\end{aligned}
$$

\begin{tabular}{|c|c|c|c|c|}
\hline $\mathrm{AgNO}_{3}$ Volume & Angle & Aspect Ratio & $\begin{array}{c}\text { Particle } \\
\text { Percentage }\end{array}$ & $\begin{array}{c}\text { Void } \\
\text { Percentage }\end{array}$ \\
\hline $5 \mu \mathrm{L}$ & $41.1^{\circ}$ & 1.43 & 0.65 & 0.35 \\
\hline $10 \mu \mathrm{L}$ & $33.2^{\circ}$ & 1.56 & 0.63 & 0.37 \\
\hline $15 \mu \mathrm{L}$ & $32.5^{\circ}$ & 1.99 & 0.73 & 0.27 \\
\hline $20 \mu \mathrm{L}$ & $29.9^{\circ}$ & 2.22 & 0.80 & 0.20 \\
\hline
\end{tabular}

Figure S6. TEM images of Pd-Au nanopyramids prepared at different amounts of $\mathrm{AgNO}_{3}$ : (a)

5, (b) 10, (c) 15, and (d) $20 \mu \mathrm{L}$. (e) Besides the average width, average length, and average aspect ratio discussed in the main text, we also used some other parameters such as angle and void percentage to further characterize the morphology. Isosceles triangles are placed to help evaluate the morphology. The parameter definition and calculation method are also shown. The typical values of morphological parameters are summarized in the table. As the amount of $\mathrm{AgNO}_{3}$ was increased, the aspect ratio changed in a similar trend as what is discussed in the main text. Meanwhile, the tip angle gradually decreased, and the particle percentage gradually increased while the void percentage steadily decreased, resulting in a sharper tip with a smaller tip size. 
(a)

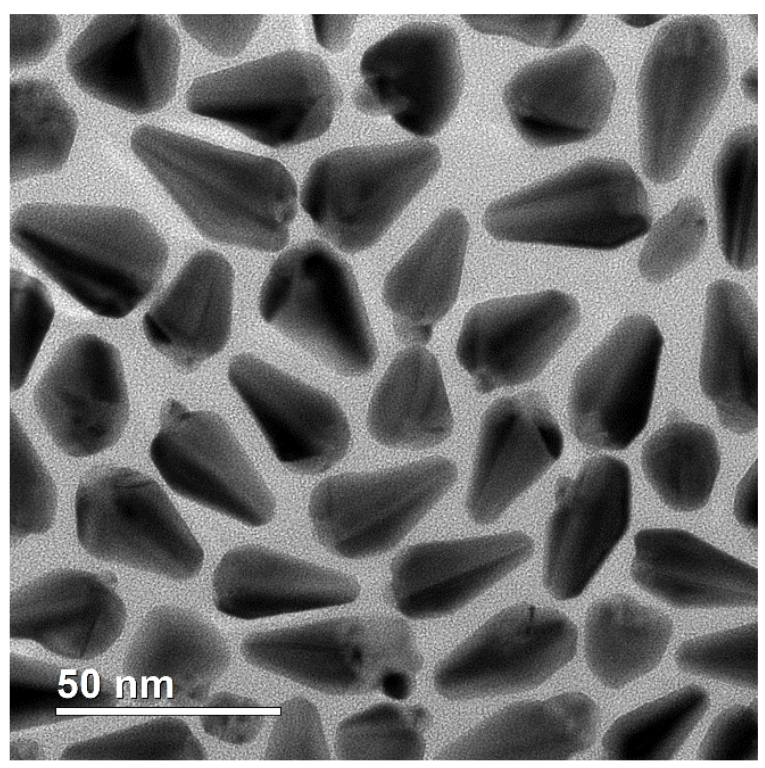

(c)

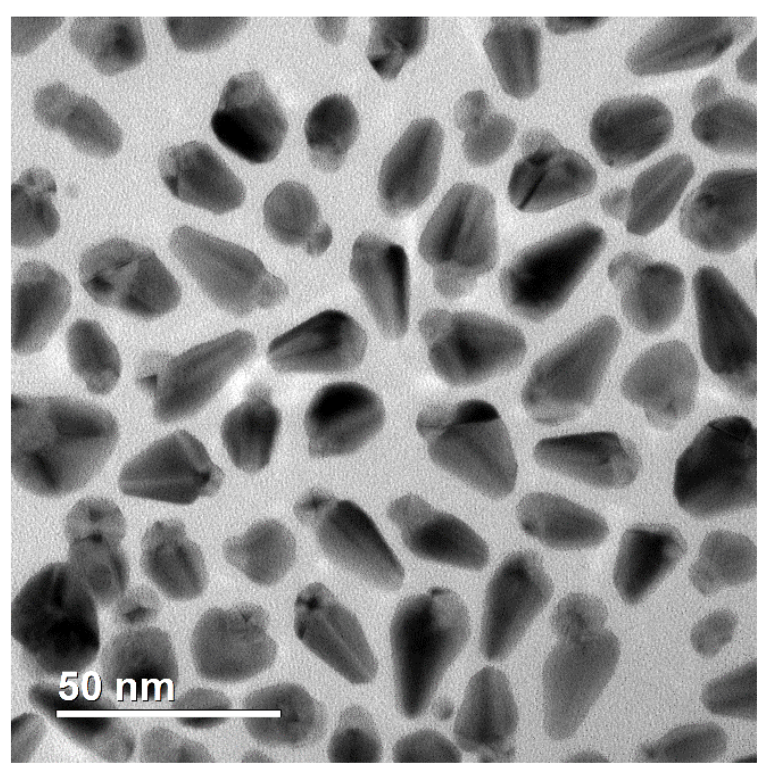

(b)

$15 \mu \mathrm{LAuCl}{ }_{4}$

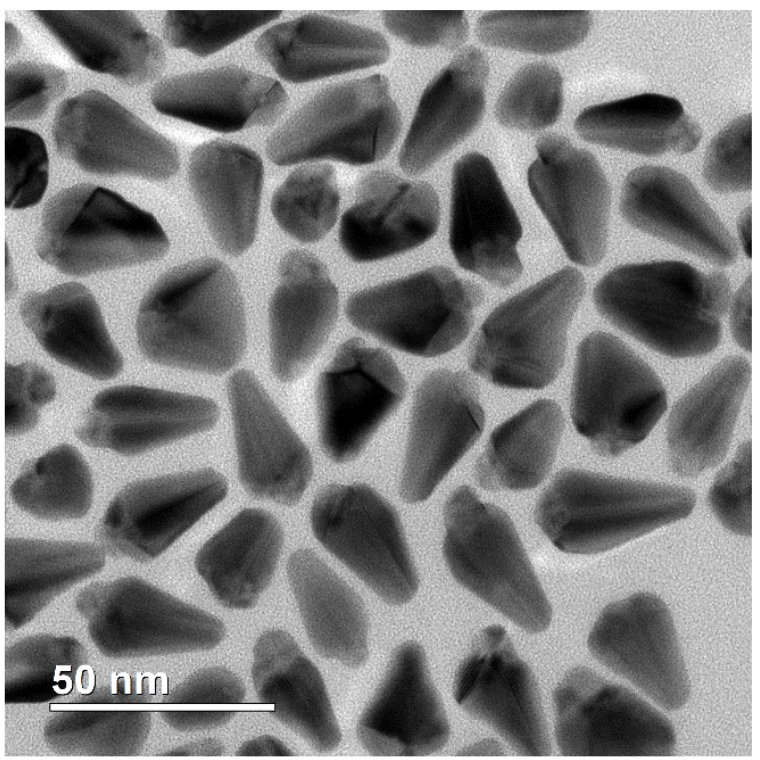

(d)

$5 \mu \mathrm{LAuCl}{ }_{4}$

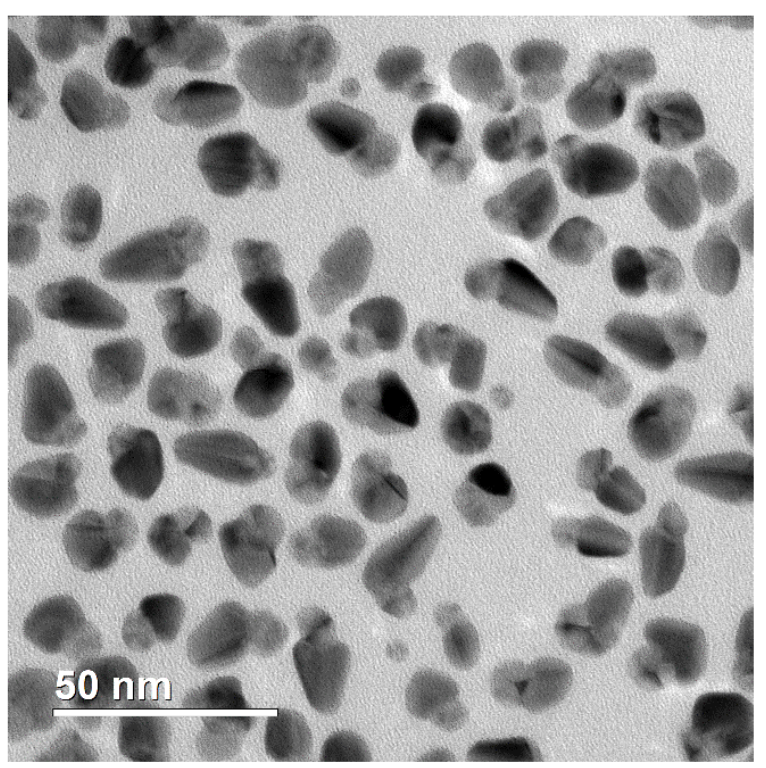

Figure S7. Pd-Au nanocrystals prepared at different amounts of $\mathrm{HAuCl}_{4}(40 \mathrm{mM})$. The size of the Pd-Au nanocrystals was reduced when the amount of $\mathrm{HAuCl}_{4}$ was decreased. 
(a) $\quad 60 \mu \mathrm{L}$ Pd seeds

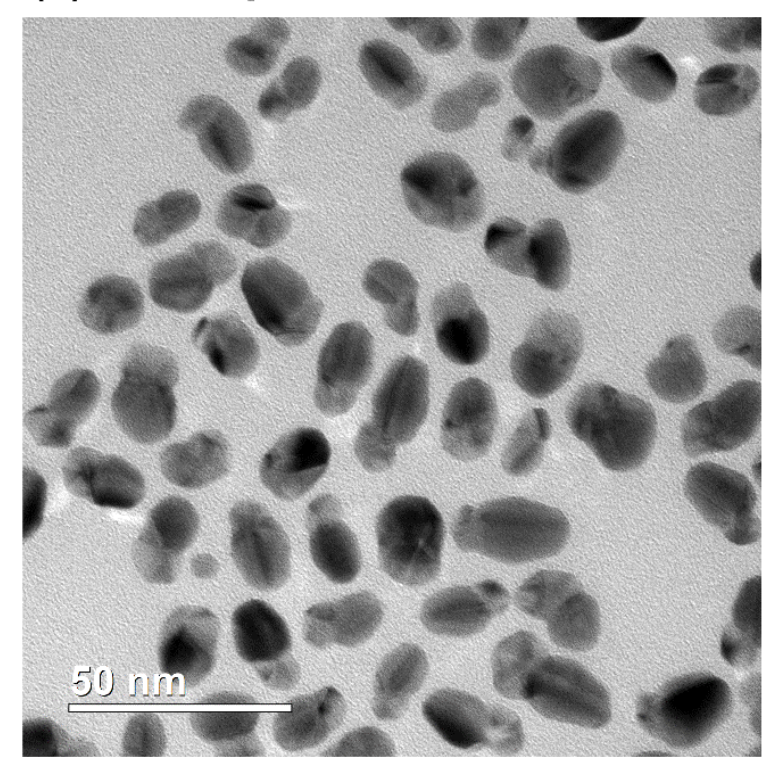

(b)

$90 \mu \mathrm{L}$ Pd seeds

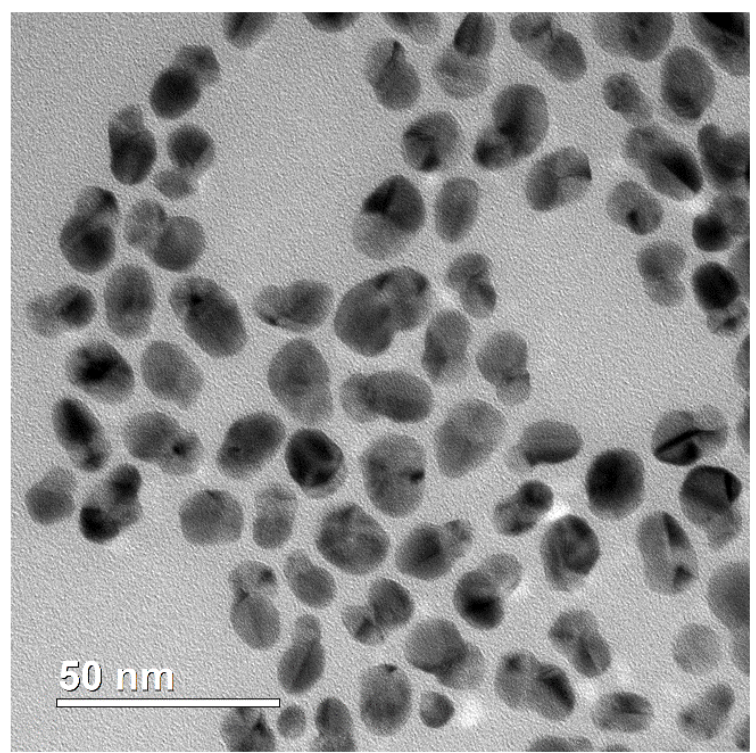

Figure S8. Pd-Au nanocrystals obtained by increasing the amount of the Pd decahedral seeds.

The size of the Au domain was reduced when the amount of the Pd seeds was increased. In the case of $90 \mu \mathrm{L}$ of Pd seeds, heterodimer-type Pd-Au nanocrystals were obtained and the lateral dimensions of the $\mathrm{Pd}$ and $\mathrm{Au}$ domains were similar to each other. 


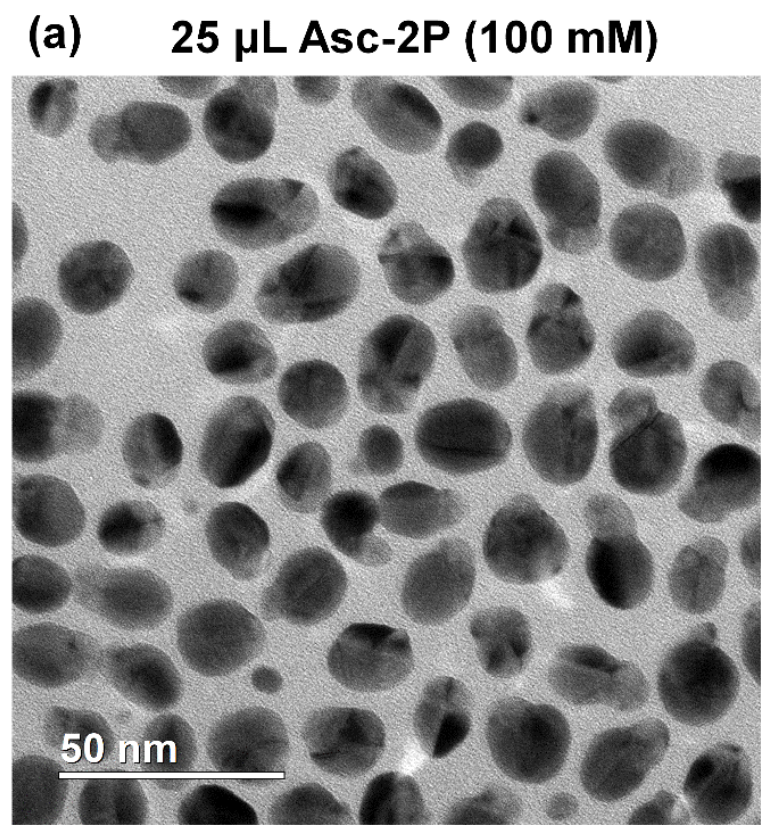

\section{(b) $5 \mu \mathrm{L}$ Asc-2P (100 mM)}

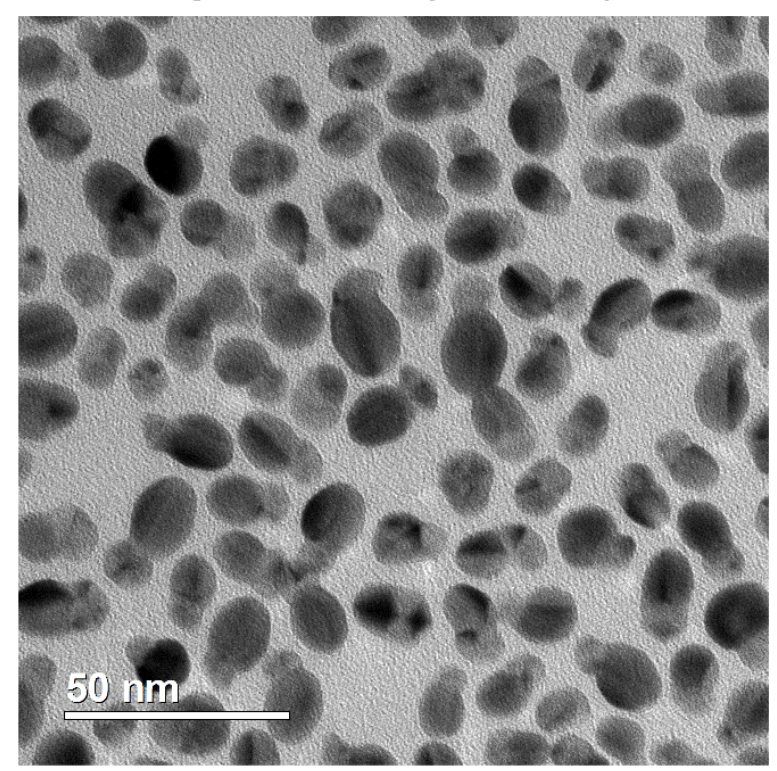

(c) $2.5 \mu \mathrm{L}$ Asc-2P (100 mM)

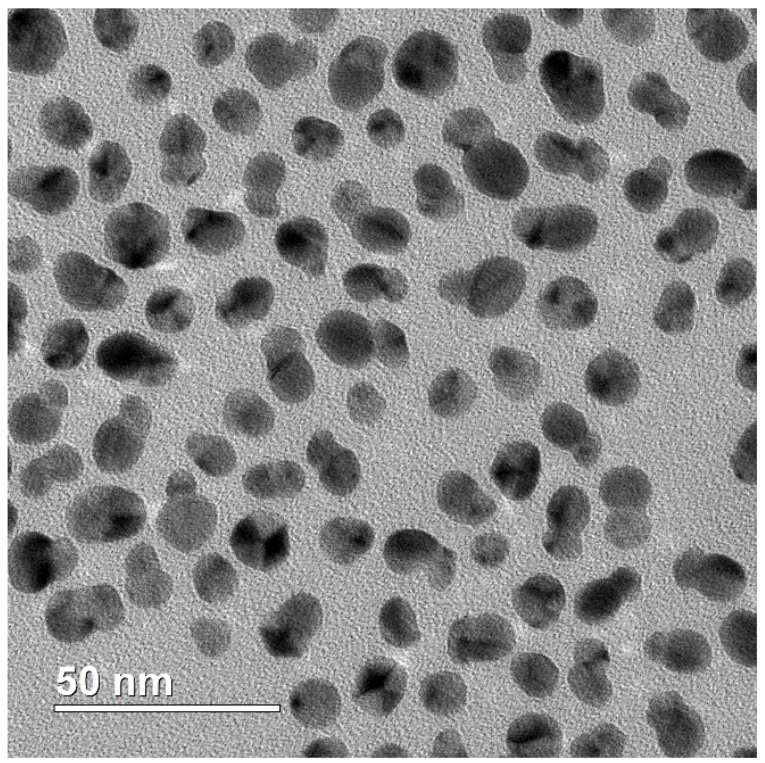

Figure S9. Pd-Au nanocrystals synthesized by decreasing the amount of Asc-2P (100 mM). In the case of $2.5 \mu \mathrm{L}$ of Asc-2P, heterodimer-type Pd-Au nanocrystals were formed, in which the lateral dimensions of the $\mathrm{Pd}$ and $\mathrm{Au}$ domains were similar to each other. 

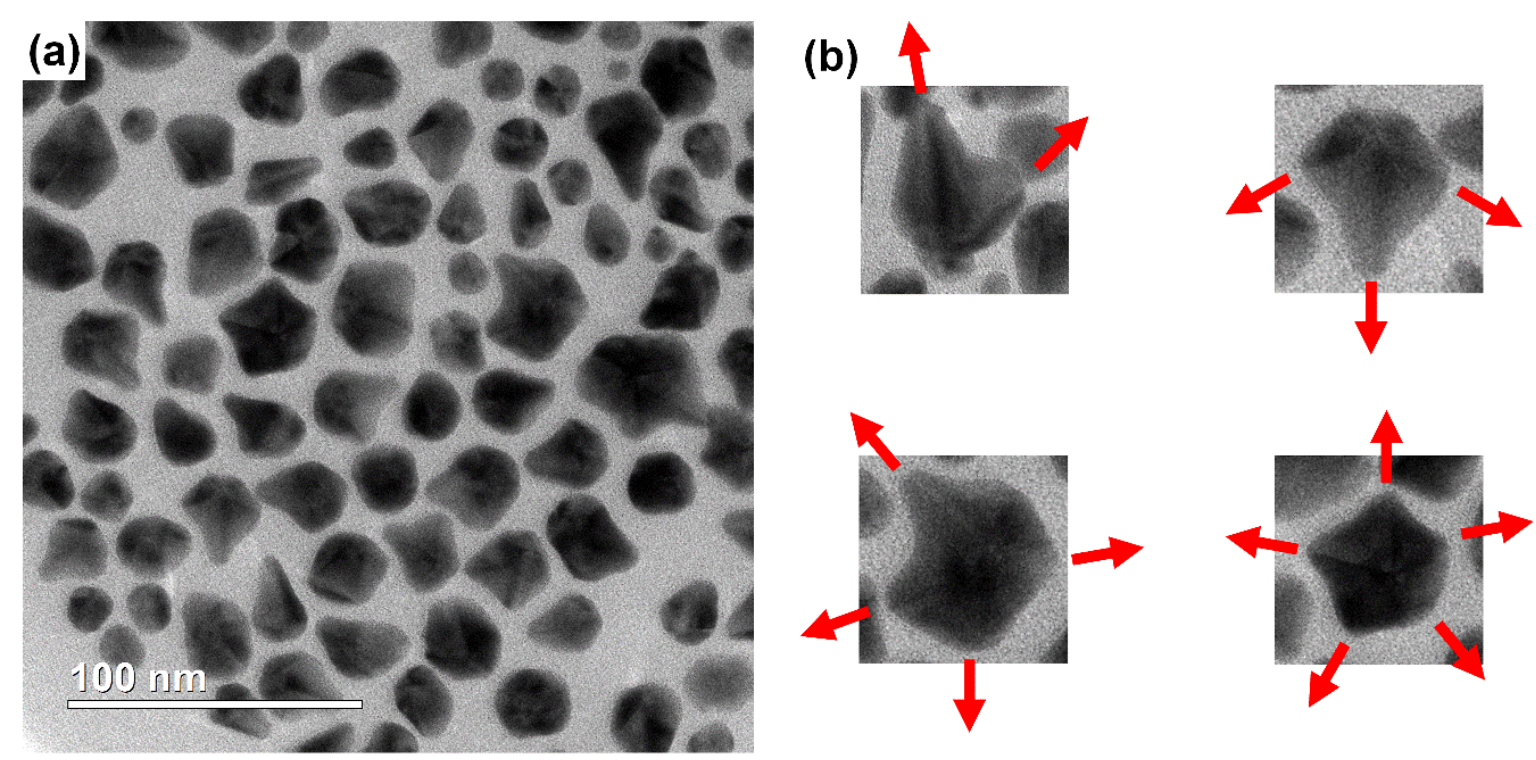

Figure S10. Pd-Au nanocrystals synthesized by increasing the amount of Asc-2P (100 mM) to $100 \mu \mathrm{L}$. In this case, we observed lateral growth from two, three, four, and five edge vertices of the decahedral seeds. 


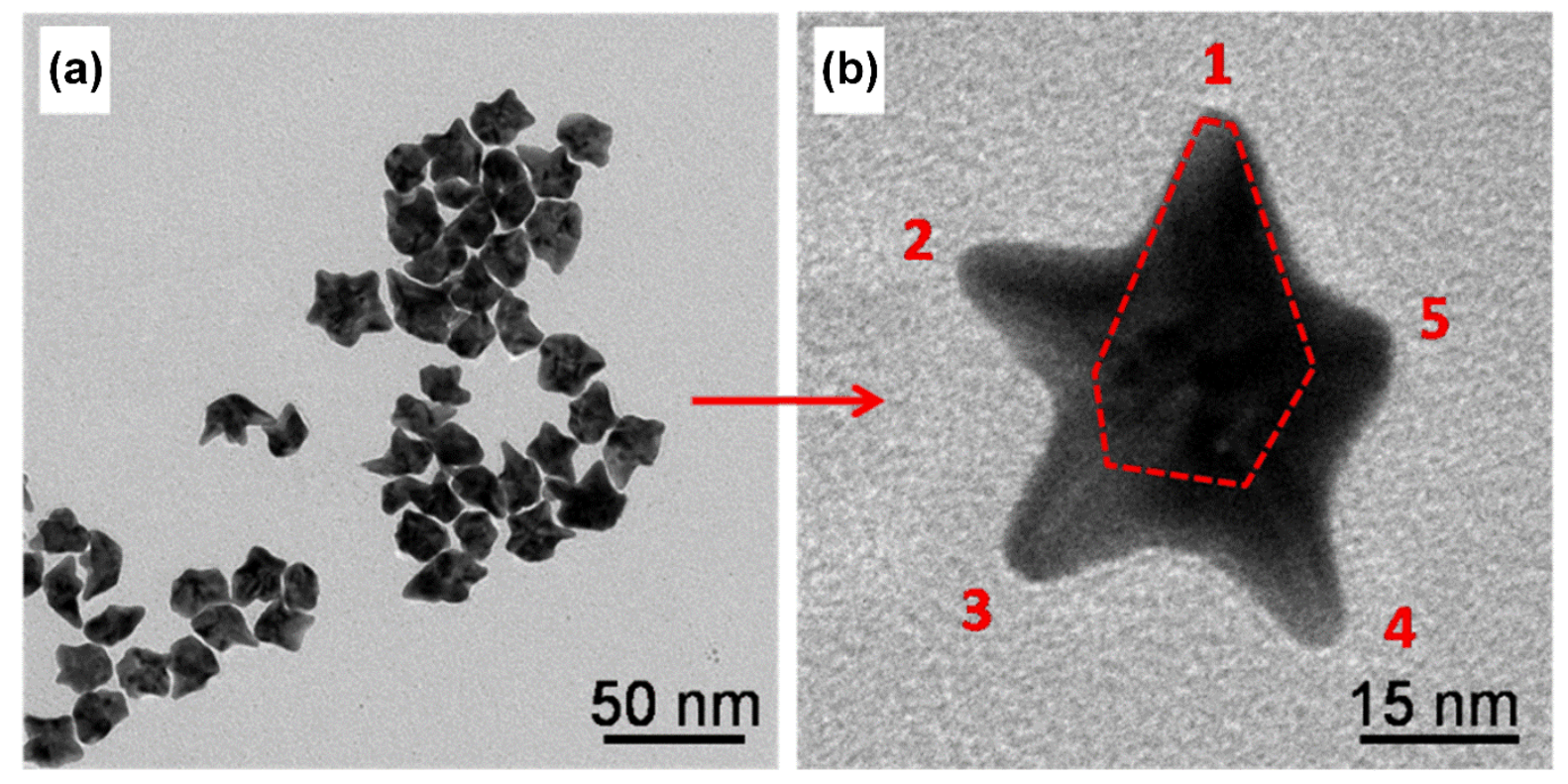

Figure S11. Pd-Au nanocrystals synthesized with AA $(50 \mu \mathrm{L}, 100 \mathrm{mM})$ serving as the reducing agent. In this case, multiple-armed Pd-Au pentagrams were formed. The dashed lines in (b) indicate the outline of a Pd-Au nanopyramid that only contained one branched arm. 